but if the patient is not already taking antiParkinsonian drugs levodopa is not a very good agent to use in these circumstances, as it takes a longer time, usually about three weeks, to show its therapeutic effect. Sacks et al reported that 12 of 25 patients treated with levodopa for the first time developed "florid respiratory crises," while an additional eight patients developed respiratory and phonatory "tics."

The mortality in Parkinsonian patients with respiratory infection is much higher than in other groups of ill elderly patients. In the past this type of incident, which should be termed a "respiratory crisis," has not attracted sufficient attention from practising physicians. If geriatricians were more alert to the danger and to the need to give additional treatmen for their patients' Parkinson's disease when respiratory infection occurs a large number of deaths in the elderly could be prevented, particularly in the winter.

B C Kundu

St Francis's Hospital,

London SE22

Sacks, O W, Kohl, W, and Messeloff. C, Lancet, $1970,1,1006$

\section{Necrotising enterocolitis}

SIR,-Your leading article on necrotising enterocolitis of the newborn (21 January, $\mathrm{p}$ 132), although commendable in its discussion of epidemiology and possible aetiology, gives little useful guidance on the indications fo surgery. Failure to improve on conservative management is a prime indication, but you make no mention of the commonest indications - peritonitis and signs of perforation with free gas seen on a plain radiograph. A review of 12 cases coming to surgery in one hospital in Bristol showed the indications to be peritonitis (6 cases), perforation (4 cases), and obstruction ( 2 cases) and in this series $75 \%$ recovered. In addition, in other published series I have studied" " "persistent bleeding from the gut" has not been an indication for surgery in any case.

University Department of Surgery, Bristol Royal Infirmary,

Bristol

Stevenson, J K, et al, American fournal of Surgery $1969,118,260$

Dudgeon, L D, et al, fournal of Pediatric Surgery, $973,8,607$.

Podiatric Surn, I, and laerber, E N, fournal of Surgery, 1971, 10, 943.

\section{Treatment of hereditary angioneurotic} oedema with methandienone

SIR,-The usual treatment of hereditary angioneurotic oedema in the past few years has been with epsilon-aminocaproic acid and possibly with fresh frozen plasma transfusions on rare occasions if a severe attack with laryngeal obstruction threatens. Androgens have also been used and Spaulding ${ }^{1}$ showed that methyltestosterone had a beneficial action. Later less masculinising androgens, fluoxymesterone and oxymetholone, ${ }^{2}$ and also danazol ${ }^{3}$ have been shown to be effective.

We report here the excellent results of reating two patients with methandienone (Dianabol). They were non-related men aged 31 and 27 and had had attacks of angioneurotic oedema and abdominal pain every few weeks for many years. In both cases the
C1 esterase inhibitor was absent or, in one case, was on one occasion only $10 \%$ of the mean normal adult value. Both patients had been helped by epsilon-aminocaproic acid but attacks still occurred every few weeks and plasma transfusions had been necessary at times.

Both patients have now been on methandienone $5 \mathrm{mg}$ twice daily for 10 and 8 months, respectively, and during these periods have remained completely clear of attacks. In addition, in both cases the level of $\mathrm{Cl}$ esterase inhibitor has returned to normal values. No adverse effects have been noted.

E M SAIHAN R P WARIN

Bristol

Spaulding, W B, Annals of Internal Medicine, 1960 53,739.
- Davis, P J, Davis, F B, and Charache, P, fohns Davis, P J, Davis, F B, and Charache,
Hopkins Medical fournal, 1974, 135, 391. "Gelfand, J A, et al, New England fournal of Medicine,

Adrenocortical suppression in workers manufacturing synthetic glucocorticoids

SIR, - I have read the paper by $\mathrm{Dr} R \mathrm{~W}$ Newton and others (14 January, p 73) three times but found no mention of the name of the offending synthetic glucocorticoid. Such reticence may be rather touching for the drug company concerned, but is surely scientifically unacceptable. With the missing name supplied their paper may well become of great interest, while without it it seems pointless and even (for those who have guessed wrongly) misleading.

Hope Hospital,

David C ANDERSON

** The authors preferred not to name th drug on the grounds that the manufacturers had been so helpful in arranging the study.ED, $B M F$

\section{Otosclerosis and the operating} microscope

SIR,-As a retired otologist I greatly appreciate the short leading articles in the $B M F$ which so often give some idea of what aspects of medical science are attracting attention at the present time. It distressed me, therefore, in the recent article on otosclerosis (14 January, $p$ 63) to find some serious inaccuracy in historical fact. To some this may seem of small importance, but as these articles are well documented they may be accepted and quoted and error then become fact. I refer to the information regarding Julius Lempert which is not in accordance with fact.

Julius Lempert never used the operating microscope; instead he used Cameron magnifying spectacles. The article referred to ${ }^{1}$ makes no mention of a microscope but refers on $p 62$ to the necessity for "powerful magnifying glasses" which are the Cameron glasses referred to above.

The credit for the introduction of the operating microscope must go to Sweden, where Professor Gunnar Holmgren pioneered the fenestration operation with great pertinacity and courage in face of failure. He stimulated workers in many countries, including Julius Lempert in America. Lempert's great contribution was the description of the one-stage operation, which was made possible by the introduction of chemotherapy. In conclusion I would add that I have seen Julius Lempert operate many times in New York and counted him as a close friend for whose surgical achievements I have great admiration.

There are other matters in this article with which one might well disagree, but these are matters of opinion. At least let us get the matters of fact correct.

I SimSON HaLL

The Library, Roval College of Surgeons,

${ }^{1}$ Lampert, J, Archives of Otolaryngology, 1938, 28, 42

\section{Threadworms in homosexual males}

SIR,-Threadworm infestation is common in childhood, when it is acquired by eating contaminated food or having contact with infected clothing or other fomites. In recent years infections have been described in homosexual males, ${ }^{1}$ but the mode of transmission in such cases has not been clearly defined. The following is a report of a young homosexual male who apparently acquired the infection during oroanal sexual intercourse.

An 18-year-old mechanic attended a department of sexually transmitted diseases complaining that he had had perianal irritation, particularly at night, for two weeks and had noted "worms" on his stool on one occasion. Threadworms in the anal canal were noted on proctoscopy. Rectal cultures for Neisseria gonorrhoeae and for Chlamydia trachomatis were negative, as were serological tests for syphilis.

He had had one sexual relationship during the preceding nine months and on that occasion, two months before attending the clinic, had had oroanal and orogenital contact only. His contact, a 20-year-old clerk, attended the clinic several days later at the request of the patient. He was asymptomatic, but a Scotch tape swab from the perianal region showed five eggs typical of those of Enterobius vermicularis. This young man had had several homosexual relationships, all casual, within the preceding six months, but none could be contacted to be examined.

Oroanal contact is a common practice among homosexual males, at least $70 \%$ of those attending this clinic having performed this at some time. While it is impossible to be absolutely certain that the patient described above acquired his infection in this way and not, for example, from contaminated fomites, the history of contact with an infected person followed by a prepatent period is strongly suggestive that this was the mode of transmission.

Glasgow

A McMillan

Markell, E K, and Voge, M, Medical Parasitology, 4th edn, p 357. Philadelphia, Saunders, 1976. Waugh, M A, Transactions of the St fohn's Hospital
Dermatological Society, 1972, 58, 224.

Central dopamine blockade in anorexia nervosa

SIR,-Dr M R Trimble (10 December, p 1541) reported a rapid weight gain in a female patient with anorexia nervosa treated by weekly injections of fluspirilene. The patient also "felt very much better" and "lost her 
obsessions about food." Reports also exist ${ }^{1}{ }^{2}$ of anorectic patients responding well to oral pimozide. In each case weight gain and general improvement were associated with disappearance of an "implacable obsession with weight"1 or a "delusion of fatness."'

Fluspirilene and pimozide are closely related members of the diphenylbutylpiperidine class of neuroleptics. They differ from the majority of such agents by being selective blockers of central dopaminergic neurotransmission, at least part of this blockade occurring in the hypothalamus. Barry and Klawans ${ }^{3}$ have demonstrated how many of the features of anorexia nervosa may be attributed to increased activity of dopaminergic neuronal systems in the hypothalamus.

Anorectic patients may be most likely to respond to a diphenylbutylpiperidine agent when a delusional disturbance of body image is central to the psychopathology. Bruch ${ }^{4}$ and others believe this to occur commonly, although substantial doubt about this must be entertained. Where such "delusional fatness" is present the patient may be considered to exhibit a monosymptomatic hypochondriacal psychosis. Patients within this general category appear to respond well to pimozide,$^{56}$ and increased central dopaminergic neurotransmission has also been implicated in this condition. ${ }^{7}$

I intend to test the above hypothesis and am currently planning a controlled study of the effects of pimozide in anorexia nervosa.

\section{TERENCE M ReILLY}

St Mary's and Maudsley Hospitals,

London

1 Plantey, F, Lancet, 1977, 1, 1105.

2 Reilly, T M, Proceedings of the Royal Society of Medicine In press. Medicine. In press.
Barry, V C, and Klawans, H L, fournal of Neural
Transmission, 1976, 38, 107.

Bruch, H, Psychosomatic Medicine, 1962, 24, 187.

'Riding, J, and Munro, A, Acta Psychiatrica Scandinavica, 1975, 52, 23.

Reilly, T M, Lancet, 1975, 1, 1385.

'Reilly, T $M$. In preparation.

\section{Cardiac arrhythmia after mushroom ingestion}

SIR,-In the past few years there has been a great increase of popular interest in fungi from those interested in natural history and in culinary experiments and from those seeking a psychotropic effect.

Many popular books quote and requote each other regarding toxic effects. One agaric that has been suspect but considered by some a case of mistaken identity ${ }^{1}$ is Coprinus atramentarius. It was therefore particularly instructive to read the report by Drs $M$ J Caley and R A Clark (24-31 December, p 1633). There seems no doubt that this toadstool has unpleasant (and dangerous?) disulfiram-like properties. It is unfortunate that a writer suggested recently in a countryman's journal ${ }^{2}$ that $C$ atramentarius could be eaten on toast at cocktail parties as a sort of "divertissement."

Some members of the British Mycological Society have been concerned with the possibility of an increace in the instances of mushroom poisoning occurring in Britain. We are also aware that there is little authentic documented information regarding the frequency and severity of poisoning. I would be pleased to hear from any reader who has experience of poisoning or allergic reaction following ingestion of species which have been determined with certainty. I will pass on such information to Mrs Ray Cowell, who is collecting the data.

May I finally defend Drs Caley and Clark in their use of the word "mushroom" (Dr A P Radford, 14 January, $p$ 112). In Britain we have no single collective term for our "champignons supérieurs." The word mushroom may be restricted to species of the genus Agaricus (which contains at least one poisonous species) by mycologists but it also serves as a general lay term for the larger fungi. This term is commonly used in the titles of books ${ }^{1}$ and headlines in newspapers, and quite correctly in the title of an article in the $B M \mathcal{A}$.

\section{P A JONES}

Avenue Villa,

Jordan, M, A Guide to Mushrooms, p 167. Blandford Dorset, Millington, 1975 Lockhart, L B, Field, 7 April 1977.
Bulletin of the British Mycological Society, 1977, 11,
151.

\section{Snap-happy parents}

SIR,-Recently much attention has been given to the importance of bonding of mothers and babies, particularly as studies have suggested a much higher incidence of non-accidental injury and associated problems in babies weighing less than $2.5 \mathrm{~kg}$ at birth or when separated from their mother either at birth or during the first year of life. ${ }^{1-4}$

Babies requiring intensive neonatal care must usually of necessity be cared for in units separated from their mothers. Similarly maternal ill health or the design of the hospital may dictate this. Many units encourage mothers to visit to handle their babies as much as possible to encourage bonding, but inevitably a gap exists. We too have followed this policy. Since October we have attempted to reinforce this by providing, as far as possible, each mother of any baby that is likely to remain in the special care unit for more than a minimal period, or which requires transfer elsewhere for further care, with a photograph taken with a Polaroid camera as suggested by Klaus and Kennel. ${ }^{*}$ This is easily done by the nursery staff and does not require the services of a hospital photography department.

To date the scheme has been enthusiastically received by the mothers and by the nursing staff of the special care nursery and postnatal wards. An unexpected complication became apparent after some weeks during rounds of the postnatal wards. It was noted that while many mothers had photographs prominently displayed, some did not. Further inquiries showed that these had usually been taken away by proud or amazed fathers.

It thus seems possible that these photographs may help bonding not only between the mother and child but also between father and child. The importance of the latter tends to receive less attention than perhaps it should and is probably even more difficult to encourage, but in our hospital at least the fathers' behaviour demonstrates that they are important and are keen to get involved in more than a merely supportive role. As a result of our recent experience we now provide two photographs of each baby, one for each parent. The cost of this is approximately $58 \mathrm{p}$ per baby and we estimate the annual cost at around $£ 50$. We consider this a small expenditure compared with the cost involved in the treatment and management of non-accidentally injured children.

We acknowledge the generosity of Wyeth Laboratories, who supplied the Polaroid camera.

\section{J A Sills}

J E HANDLEY

Paediatric Department,

Bangour General Hospital

Lynch, M A, and Roberts, J, British Medical fournal, $1977,1,624$.

Lynch, M A, Lancet, 1975, 2, 317

Sills, J A, Thomas, L J, and Rosenbloom, L, Developmental Medicine and Child Neurology, 1977, 19, 26. Paediatrics 5 , ed D Hull. Edinburgh, Churchill Livingstone, 1976.

\section{Bronchiectasis in acute leukaemia}

SIR,-We thank Dr J W $M$ van der Meer and his colleagues (14 January, p 111) for their comments on our paper (1 October, p 857) and their interesting case report. We noted that an improvement on chest $x$-rays may have been influenced by prophylactic rotating antibiotics, but we did not "ascribe great value" to the use of antibiotics, which we believe is still an open question. Prophylactic antibiotics are not in fashion, but a recent double-blind controlled trial reported from St Jude Children's Research Hospital, Memphis, of cotrimoxazole in patients on immunosuppressive therapy is of interest. ${ }^{1}$ The authors showed a significant reduction of bacterial infections as well as of Pneumocystis carinii pneumonia in the treated group.

The patient with aplastic anaemia and bronchiectasis reported by $\mathrm{Dr}$ van der Meer and his colleagues is not exactly analogous to our cases as children on combination chemotherapy are immunosuppressed as well as myelosuppressed. Like their patient, regular physiotherapy was an integral part of the management of our children. One of these children has now stopped all combination chemotherapy and prophylactic antibiotics have been stopped as well. The Dutch group's reliance on sputum cultures for determining the aetiology of lower respiratory tract infections is not applicable to children, in whom traditional bacteriological techniques are frequently irrelevant and may be misleading when compared with needle aspirates of the lung. ${ }^{2}$

P J KEARNEY C R KERSHAW P A STEVENSON

University Department of

Child Health,

Royal
Bristol

1 Hughes, W T, et al, New England fournal of Medicine, Hughes, $\mathrm{W}$ T, et al,

Silverman, M, et al, Archives of Disease in Childhood,
1977, 52, 925 .

\section{Ferritin and iron overload}

SIR,-In reply to Dr M Worwood and Mr M Wagstaff (21 January, p 177) I should like to make the following points.

(1) In our investigation (19 November, p 1327) tumour ferritin isoelectric point was determined in an LKB 110-ml focusing column.

(2) I agree with their comment regarding the form of ${ }^{59} \mathrm{Fe}$ in the serum of this patient. However, unlike many of the other patients with 